\title{
Comparison of efficacy of Ledermix and Calcium hydroxide in the management of deep caries
}

\author{
${ }^{*}$ Dr. Fahd A. A Karim ${ }^{1}$, Dr. Asma Sultana ${ }^{2}$, Dr. It. Col. Hannan Shiekh ${ }^{3}$, Dr. Md. Ashif Iqbal ${ }^{4}$,
} Dr. Puja Shrestha ${ }^{5}$, Dr. Md. Toufiqur Rahman ${ }^{6}$, Dr. Tarannum Tasnim

\section{AFFILIATION:}

1. Dr. Fahd A. A. Karim, (BDS, DDS, FCPS)

Assistant Professor, Dept. of Conservative Dentistry \& Endodontics Update Dental College, Dhaka, Bangladesh

2. Dr. Asma Sultana BDS, DDS

Associate Professor, Department Science of Dental materials Update Dental College, Dhaka, Bangladesh

3. Dr. Lt. Col. Hanann Shiekh, BDS, DDS, MCPS, FCPS

Classified Endodotics \& Head,

Dept of Conservative Dentistry \& Endodontics,

Military Dental Centre Dhaka, Dhaka Cantt. Bangladesh

4. Dr. Md. Ashif Iqbal, BDS, DDS (BSMMU)

Associate Professor, Dept. of Periodontology \& Oral Pathology Update Dental College, Dhaka, Bangladesh

5. Dr. Puja Shrestha, BDS

Intern Doctor

Update Dental College, Dhaka, Bangladesh

6. Dr. Md. Toufiqur Rahman, BDS, MPH

MSC On course in Universiti Sains Malaysia

Lecturer, Update Dental College, Dhaka, Bangladesh

7. Dr. Tarannum Tasnim Pia, BDS, MPH (NIPSOM)

Senior Lecturer, Dept. of Science of Dental materials Update Dental College, Dhaka, Bangladesh

\section{Article info.}

Received: 10 October 2019

Accepted: 8 November 2019

Volume: 10, Issue-1 April, 2020

\section{DOI: https://doi.org/10.3329/updcj.v10i1.46685}

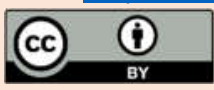

(c) Authors retain copyright and grant the journal right of first publication with the work simultaneously licensed under Creative Commons Attribution License CC - BY 4.0 that allows others to share the work with an acknowledgment of the work's authorship and initial publication in this journal.

https://creativecommons.org/licenses/by/4.0/

Publisher: Update Dental College, Dhaka, Bangladesh

Web: $w$ ww.updatedentalcollege.edu.bd

E-mail: updci@hotmail.com

\author{
* Corresponding Author \\ Dr. Fahd A. A. Karim, (BDS, DDS, FCPS) \\ Assistant Professor, \\ Dept. of Conservative Dentistry \& Endodontics \\ Update Dental College, Dhaka, Bangladesh \\ Email: fahdkarim1792@gmail.com
}

\section{Citation}

Karim A A, Sultana A, Shiekh S H, Iqbal MA, Shrestha P, Rahman T et al. Comparison of efficacy of Ledermix and Calcium hydroxide in the management of deep caries .UpDCJ.2020 Apr;10(1):6-12. Available from: DOI:

https://doi.org/10.3329/updcj.v10i1.46685

\section{ABSTRACT}

Background:Pulp capping is a treatment that enables pulp to recover and maintain its vitality and function by applying a protective agent to an exposed pulp. $\mathrm{Ca}(\mathrm{OH})_{2}$ has been considered the gold standard for this procedure. Despite its wide use, $\mathrm{Ca}(\mathrm{OH})_{2}$ is not ideally suited for pulp capping. Recently ledermix cement used for indirect pulp capping material in the outer world broadly.Objective: To assess the clinical and radiological evidence of the formation of secondary dentin and compare the degree of short time post operating pain after indirect pulp treatment. Methods: A Randomized control trial in vivo study was directed in the Department of Conservative Dentistry and Endodontics, Faculty of Dentistry, Bangabandhu Sheikh Mujib Medical University for one year (January 2012-January 2013). We took the patients with 40 deep carious permanent teeth as a sample. The selected teeth were divided into two test groups. All odd number teeth (20) were included in group-1(where pulp capping was done with ledermix cement). All even number teeth (20) were included in group-2(where pulp capping was done with $\mathrm{Ca}(\mathrm{OH}) 2$ ). We assessed all the patients clinically and radiographically at the interval of 3,6 , and 12 months simultaneously for the assessment of dentinal bridge formation and also collected data was analyzed using statistical package for social science (SPSS) version 17.Results: Among the full scale 40 models, ledermix (20) and $\mathrm{Ca}(\mathrm{OH}) 2(20)$, minor to direct irritaion of the teeth was experienced premium to treatment and found comparable in the two gatherings. Regardless, after $24 \mathrm{hrs}$ of treatment, this value was shockingly higher in the $\mathrm{Ca}(\mathrm{OH}) 2(\mathrm{p}<0.01)$ group than in the Ledermix gathering ( $p<0.001$, t-test). Following 7 days, there was no basic differentiation between them. Follow up evaluation revealed, failure of 3 teeth treated with $\mathrm{Ca}(\mathrm{OH}) 2$ and 2 teeth treated with ledermix due to pain and swelling. The remaining 35 teeth radiated an impression of being clinically and radiologically successful a year postoperatively.Conclusion: No post-operative pain was experienced in both groups in the long term. However, within the first hours after cementation, there was a sensation of pain significantly higher in the $\mathrm{Ca}(\mathrm{OH}) 2$ group than in the Ledermix group. Ledermix can be considered a predictable treatment and may be an alternative to calcium hydroxide in indirect pulp capping.

\section{KEYWORDS: Leadermix, Calcium hydroxide, Deep caries}

\section{INTRODUCTION}

Concepts and treatment principles of deep carious lesions are an area of debate and constant change (Bjørndal L, Kidd EA. 2005). The true clinical status of the pulp tissue under deep carious lesions is not easy to evaluate and therefore makes it difficult to diagnose tooth vitality precisely (Bjørndal L.2002). An important priority in the treatment of deep carious lesions is to preserve pulp vitality (Miyashita $\mathrm{H}$ et al.2007). The outcomes of pulp exposure from caries, trauma or during tooth preparation can be extreme, bringing about pain and infection which is then require either root canal treatment or extraction. Due to extraction, the common tooth needs to forfeit and should be replaced with a fake one. Endodontic treatment and tooth restoration require multiple visits and significant costs. Henceforth, an elective methodology of extraction or endodontic treatment is pulp capping, in which a 
medicament is straightforwardly put over the exposed pulp (direct pulp capping), or a cavity liner or sealer is set over lingering caries (indirect pulp capping) to keep up pulp vitality. 6 to 8 weeks is required for satisfactory remineralization of the cavityt floor (Greely CB et al.1981) (Sayegh FS 1968) following indirect pulp capping. This attractive result is the essence of the maintenance of a patent seal by the transitory and final restorations against microleakage. In the literature retrospective and prospective studies showed that in both dentitions the success rate for IPT is similar, ranging from $73 \%$ to $95 \%$ after 2 weeks to 11 years of follow up (Oliveira EF et al. 2006).To search the ideal vital pulp therapy material, researchers investigate many different materials such as $\mathrm{Ca}(\mathrm{OH}) 2$ compound, Zinc oxide, Calcium phosphate, polycarboxylate cement, antibiotic and growth factor combination, Resin modified glass ionomer cement and recently MTA. Other studies have included ledermix, antibiotic mix, glycerrhetinic acid, potassium nitrate and dimethyl isosorbide (Miyashita $\mathrm{H}$ et al. 2007). But each of these pulp capping materials has its limitations and defects.

At present Calcium hydroxide is the most commonly used indirect pulp capping material and was introduced to the dental profession in 1921 which has been well considered as the "gold standard" of direct pulp capping material for several decades (Baume L, Holz J.1981). Many researchers agree that calcium hydroxide encourages the formation of dentinal bridges. (Kopel.1992;). It has some disadvantages also. The self cure formulations are profoundly soluble and cause a disintegration after some time (Prosser $\mathrm{H}$ et al .1982). It has no instinctive adhesive characteristics and outfits a poor seal (Kitasako et al.2008). Another remark noted of calcium hydroxide is the presence of alleged "tunnel defects" in reparative dentin shaped underneath calcium hydroxide pulp caps (Kitasako et al.2008)(Cox C et al.1996). The disintegration of calcium hydroxide under restorations associated with defects in the dentinal bridge can provide microorganisms with a pathway for penetration into pulpal tissue and the subsequent stimulation of circulating immune cells, inducing pulpal irritation and potential pulpal calcification and obliteration.

The anti-inflammatory properties of glucocorticoids were first appreciated and utilized as an addition to endodontic therapy almost half a century ago (Blitzer MH.1956). Researchers have shown that the application of corticosteroid for a short period was effective to control inflammation in the pulp tissue without determining changes in the healing process (Miyashita $\mathrm{H}$ et al .2007). Ledermix paste (Lederle pharmaceuticals, Wolfratshausen, Germany) is a glucocorticosteroid antibiotic compound developed by Prof Andre Schroeder from Switzerland in 1960 and was released for sale in Europe by Lederle pharmaceuticals in1962 (Athanassiadis B et al. 2007). It is a combination of the demeclocycline- $\mathrm{HCl}$ (at a concentration of $3.2 \%)$, and triamcinolone acetonide (concentration 1\%), in a polyethylene glycol base. The triamcinolone is present in Ledermix paste at a concentration of $1.0 \%$ and in Ledermix Cement at a concentration of

7 | P a g e
$0.67 \%$ (Abbott PV, Leow N. 2009). The sole reason for adding the antibiotic component to Ledermix was to prevent overgrowth of microorganisms and compensate for what was perceived at the time to be a possible corticosteroid-induced reduction in the host immune response (Athanassiadis B et al.2007). Ledermix cement is a similar agent in that it contains triamcinolone and demeclocycline, but, the active components are contained in a hard-setting base and have lower concentrations ( $0.67 \%$ and $2.0 \%$ respectively) than in the paste (Hume WR, Kenney AE, 1981). But, as it is hardsetting cement, it is preferred for pulp capping rather than using the paste form. After the triamcinolone is released from Ledermix Cement, the remaining cement is a zinc oxideeugenol material with calcium hydroxide. Both of these components have well known therapeutic effects on the pulp. Calcium hydroxide has beneficial effects on the healing of dental pulps and the formation of reactionary/reparative dentine (Eidelman et al.1965) (Graham et al. 2006). Whilst the eugenol has both anti-inflammatory and anti-bacterial action depending on the concentration reaching the dentine and pulp as it is released by progressive hydrolysis occurring at the cavity floor(Hume WR.1984) (Hume WR. 1986). Demeclocycline is used for its antimicrobial action and it also has some limited ability to inhibit the clastic cells involved in root resorption (Heithersay GS et al. 1990) (Pierce AM, Lindskog S.1987) (Pierce et al.1988).

\section{METHODOLOGY}

A Randomized control trial in vivo study was conducted in the Department of Conservative Dentistry and Endodontics, Faculty of Dentistry, Bangabandhu Sheikh Mujib Medical University for one year (January 2012-January 2013). We took patients with 40 deep carious permanent teeth as a sample. The selected teeth will be divided into two test groups. All odd number teeth will be included in group-1(where pulp capping will be done with ledermix cement). All even number of teeth will be included in group-2(where pulp capping will be done with $\mathrm{Ca}(\mathrm{OH}) 2$ ).An individual patient's data including case history, clinical assessment method of diagnosis (clinical \& radiological), treatment plan and periodic follow-up of the patients were recorded. Diagnosis of vital teeth for indirect pulp capping was confirmed by vitality tests, clinical and radiological evaluation.

A standardized structured data collecting instrument was used to collect necessary information of the study subject that included:

\section{A) History of patient}

B) Clinical examination - Detailed examination of both groups of Pulp capping teeth. Inspection and palpation were done to assess the following parameters.1. Pain assessment by visual analog scale (VAS). 2. Assessment of swelling by Fluctuation test. 3. Assessment of mobility 4. Assessment of Fistula by sinograph. 5 Assessment of tenderness by percussion:

\section{C) Radiographical Evaluation;}

1. Periapical or Interradicular radiolucency. 2. Internal Root Resorption. 3. External Resorption.

Website: https://www.banglajol.info/index.php/UpDCJ 
D) Follow up Data Sheet: All the parameters mentioned above were examined with the same technique before pulp capping and follow up periods were day 1 , day 3 , day 7 , 3rd-month 6th month, and 12 months and data were recorded in the followup chart (Appendix-II).

\section{STUDY PROCEDURE:}

Thorough history taking clinical examination and radiograph was taken for each case. Those failed to meet inclusion criteria were rejected. Thus, a total of 40 teeth that fulfill the inclusion criteria were selected for the study. The occupation, socioeconomic condition, general health status, drug history and past dental history of the patients, spontaneous pain or pain during the night time was obtained by face to face interviews and was recorded in a prefixed questionnaire by a patient. Percussion and pulp sensitivity tests were performed and radiographs were examined to assess pulpal health. The patient's symptoms, clinical signs, and radiographic shreds of evidence were recorded.

\section{STUDY TOOTH PREPARATION:}

Step- I:

- Disinfection of the operative field and proper sterilization of instruments was ensured.

- Hand gloves, the face mask was used in every case in an aseptic manner.

- Local anesthesia was administered.

- Isolation of teeth was done with a cotton roll and saliva ejector.

Step - II: Firstly, surrounding caries were removed by using no. \#4 diamond bur at high-speed with air/water spray was used to remove enamel and to reach caries lesion. Infected dentin from cavity walls was firstly removed with a spoon excavator \#17 followed by low-speed round carbide burs compatible with the size of the cavity. Care was taken to avoid pulp perforation. The excavation was performed carefully to remove the carious dentin, leaving the dry demineralized affected dentin.

Step- III: Patients in Group-1, the following method was followed: - ledermix powder and liquid (sigma pharmaceuticals) were mixed according to the manufacturer's proposals with a plastic spatula, in the proportion 3:1.After mixing, ledermix cement was applied over the base of the cavity. After the setting of ledermix cement, the remainder of the cavity was loaded up with Fuji-IX Glass ionomer cement. The bite was checked for evacuating any nearness of high spots and Varnish was applied over the Glassionomer Filling. A postoperative radiograph was taken.

Patients in Control Group-2, the following technique was followed: $\mathrm{Ca}(\mathrm{OH}) 2$ powder was mixed in with saline to a thick consistency. The paste was deliberately put over the base of the cavity. The remainder of the cavity was filled separately with Glassionomer (Fuji-IX) Cement and Varnish were applied over the Glassionomer Filling. A post-operative radiograph was taken.
RESULT:

The study involved patients with 40 deep carious teeth which required pulp capping treatment. The results of all the cases which were treated with Ledermix and $\mathrm{Ca}(\mathrm{OH}) 2$ as indirect pulp capping agents are showed in the following table.

Table-I. Age and sex distribution of the respondents

\begin{tabular}{|c|c|c|c|c|c|}
\hline Variables & $\begin{array}{l}\text { GroupA } \\
(n=20)\end{array}$ & & $\begin{array}{l}\text { Group } \\
(n=20)\end{array}$ & & $\begin{array}{l}P \\
\text { value }^{a}\end{array}$ \\
\hline \multicolumn{6}{|c|}{ Age(years) } \\
\hline Mean $\pm S D$ & $26.15 \pm 4.83$ & & $28.00 \pm 4.82$ & & $0.233^{\text {ns }}$ \\
\hline \multirow[t]{2}{*}{ Range } & $18-36$ & & $22-38$ & & \\
\hline & No. & (\%) & No. & (\%) & $\begin{array}{l}P \\
\text { value }^{b}\end{array}$ \\
\hline 85 & 9 & 45.0 & 7 & 35.0 & \\
\hline $26-30$ & 7 & 35.0 & 7 & 35.0 & $0.723^{\text {ns }}$ \\
\hline$>30$ & 4 & 20.0 & 6 & 30.0 & \\
\hline \multicolumn{6}{|l|}{ SEX } \\
\hline Male & 11 & 55.0 & 11 & 55.0 & \\
\hline Female & 9 & 45.0 & 9 & 45.0 & $1.000^{\mathrm{ns}}$ \\
\hline
\end{tabular}

Group A: Treated with Ledermix ,Group B: Treated with Calcium hydroxide unpaired Student's 't' test, big-square test, $\mathrm{ns}=$ Not significant

Table-I shows the distribution of age and sex of the study subjects. In group A and group B subjects, respectively, $9(45 \%)$ and $7(35 \%)$ patients belonged to age group $<25$ years, 7 (35\%) each belonged to age group 26-30 years, and 4 $(20 \%)$ and $6(30 \%)$ belonged to age group $>30$ years. Mean \pm SD age in group $A$ was 26.15 \pm 4.83 (range 18-36) and in Group B was 28.00 \pm 4.82 (range 22-38) years. None showed a significant difference.

Sex also showed no significant variation between the two study groups. In both group A and group B, there were 11 (55\%) males and 9 (45\%) females.

Table-II. Pretreatment and post-treatment status of pain (VAS)

\begin{tabular}{|c|c|c|c|}
\hline Pain(VAS) & Group A & Group B & $P$ value \\
\hline \multicolumn{4}{|c|}{ Pretreatment } \\
\hline $\mathbf{n}$ & 20 & 20 & \\
\hline Mean \pm SD & $4.20 \pm 1.28$ & $4.50 \pm 1.19$ & $0.448^{\text {ns }}$ \\
\hline Range & $3.00-6.00$ & $3.00-6.00$ & \\
\hline \multicolumn{4}{|l|}{ At day-1 } \\
\hline $\mathrm{n}$ & 20 & 20 & \\
\hline Mean \pm SD & $0.90 \pm 1.62$ & $2.85 \pm 1.73$ & $0.001^{* *}$ \\
\hline Range & $0.00-7.00$ & $0.00-7.00$ & \\
\hline \multicolumn{4}{|l|}{ At day-1 } \\
\hline n & 20 & 20 & \\
\hline Mean \pm SD & $0.70 \pm 2.15$ & $1.20 \pm 1.85$ & $0.436^{\text {ns }}$ \\
\hline Range & $0.00-7.00$ & $0.00-8.00$ & \\
\hline \multicolumn{4}{|l|}{ At day-1 } \\
\hline n & 18 & 19 & \\
\hline Mean \pm SD & $0.00 \pm 0.00$ & $0.37 \pm 1.21$ & $0.206^{\mathrm{ns}}$ \\
\hline Range & & $0.00-5.00$ & \\
\hline
\end{tabular}

NOTE: Pain (VAS) was absent at day 7, and 6th, 9th and 12th months, hence data is not shown in above table,Group A: Treated with Ledermix Group B: Treated with Calcium hydroxide, Unpaired Student's, ' $t$ ' test, ns = Not significant** $=$ Significant at $\mathrm{P}<0.01$

Table-II shows pretreatment and post-treatment status of pain (VAS). Mean $( \pm S D)$ pain (VAS) at pretreatment showed no significant difference between group A (4.20 \pm 1.28$)$ and group B (4.50 \pm 1.19$)$; at day 1 , the difference (group A $0.90 \pm 1.62$ vs group $B 2.85 \pm 1.73$ ) was significant $(P<0.01)$; and at 3 months, no significant difference was observed between groups (group $A 0.00 \pm 0.00$ and group B $0.37 \pm 1.21$ ). On day 7 , and months 6,9 and 12 , the pain was absent in 
both groups of patients.

Table-III. Pre-treatment and posttreatment intensity of pain

$\begin{array}{llllll}\text { Pain } & \text { Group } & & \text { Group } & & \text { P value } \\ \text { Intensity } & \text { A } & & \text { B } & \\ & \text { No. } & \text { (\%) } & \text { No. } & \text { (\%) } & \\ \text { aPre- } & & & & & 0.507^{\text {ns }}\end{array}$

treatment

\begin{tabular}{|lllllll|}
\hline $\mathbf{n}$ & 20 & & 20 & & \\
\hline Mild & 8 & 40.0 & 6 & 30.0 & \\
\hline Moderate & 12 & 60.0 & 14 & 70.0 & $0.0001^{* * *}$ \\
\hline $\begin{array}{l}\text { aAt day 1 } \\
\text { n }\end{array}$ & 20 & & & & \\
\hline None & 11 & 55.0 & 1 & 5.0 & \\
\hline Mild & 8 & 40.0 & 11 & 55.0 & \\
\hline Moderate & 0 & 0.0 & 8 & 40.0 & \\
\hline Severe & 1 & 5.0 & 0 & 0.0 & \\
\hline aAt day 3 & & & & & $0.003^{* *}$ \\
\hline n & 20 & & 20 & & \\
\hline None & 18 & 90.0 & 10 & 50.0 & \\
\hline Mild & 0 & 0.0 & 9 & 45.0 & \\
\hline Moderate & 0 & 0.0 & 0 & 0.0 & \\
\hline Severe & 2 & 10.0 & 1 & 5.0 & \\
\hline bAt month 3 & & & & & $0.486^{\text {ns }}$ \\
\hline n & 18 & & 19 & & \\
\hline None & 18 & 100.0 & 17 & 89.5 & \\
\hline Mild & 0 & 0.0 & 2 & 10.5 & \\
\hline
\end{tabular}

NOTE: Pain was absent at day 7 , and 6 th, 9 th and $12^{\text {th }}$ months follow up, hence data not shown in above table, Group A: Treated with Ledermix

Group B: Treated with calcium hydroxide, aChi-square test/bFisher's Exact test Ns $=$ Not significant ${ }^{* *}=$ Significant at $\mathrm{P}<0.01 * * *=$ Significant at $\mathrm{P}<0.001$

Table-III shows pretreatment and post-treatment intensity of pain. Pretreatment pain intensity showed statistically no significant variation between groups; in group A and group B, respectively, the pain was mild in 8 $(40 \%)$ and $6(30 \%)$, and moderate in $12(60 \%)$ and $14(70 \%)$. At day 1 , a variation of pain intensity was significant $(\mathrm{P}<0.001)$, no pain in $11(55 \%)$ and 1 (5\%), mild in $8(40 \%)$ and $11(55 \%)$, and moderate in none and $8(40 \%)$. At 3 also, variation of pain intensity was significant $(P<0.01)$, no pain in $18(90 \%)$ and $10(50 \%)$, mild pain in none and $9(45 \%)$, moderate pain in none, and severe pain in $2(10 \%)$ and $1(5 \%)$. At month 3 , the intensity of pain showed no significant variation between groups, absent in $18(100 \%)$ and $17(89.5 \%)$, and mild in none and $2(10.5 \%)$ in group $A(n=18)$ and group $B(n=19)$, respectively. There was no pain at day 7, and months 6,9 and 12 .

Table-IV. Pretreatment and post-treatment clinical evaluation

a) Palpation pain

\begin{tabular}{|llllll}
\hline Status & Group A & \multicolumn{3}{l}{ Group B } & P value \\
\hline At day 3 & No. & (\%) & No. & (\%) & $1.000^{\text {ns }}$ \\
\hline $\mathbf{n}$ & 20 & & 20 & & \\
\hline Present & 1 & 5.0 & 1 & 5.0 & \\
\hline Absent & 19 & 95.0 & 19 & 95.0 & \\
\hline At month 3 & & & & & $0.486^{\text {ns }}$ \\
\hline $\mathbf{n}$ & 18 & & 19 & & \\
\hline Present & 0 & & 2 & 10.5 & \\
\hline Absent & 18 & 100.0 & 17 & 89.5 & \\
\hline
\end{tabular}

NOTE: Palpation pain was absent at pretreatment, days 1 and 7, and 6th, 9th and 12th months, hence data is not shown in above table, Group A: Treated with Ledermix

Group B: Treated with calcium hydroxide, Fisher's Exact test, ns = Not significant Table-IV shows pretreatment and post-treatment clinical evaluation of pain. At day 3 , palpation pain showed statistically no significant variation between group $A$ and group B, the pain was present in $1(5 \%)$ each and absent in 19 (95\%) in each. At 3rd month also variation was not significant, the pain was present on only $2(10.5 \%)$ of group B patient $(n=19)$ and absent on all $18(100 \%)$ of group A patient $(n=18)$. Palpation pain was absent at pretreatment, days 1 and 7 , and months 6,9 and 12 .

\section{b) Percussion pain}

\begin{tabular}{|llllll|}
\hline Status & Group A & (\%) & Group B & $(\%)$ & P value \\
\hline At day 3 & & & & & $1.000^{\text {ns }}$ \\
\hline $\mathbf{n}$ & 20 & & 20 & & \\
\hline Present & 1 & 5.0 & 1 & 5.0 & \\
\hline Absent & 19 & 95.0 & 19 & 95.0 & \\
\hline At month 3 & & & & & $0.486^{\text {ns }}$ \\
\hline $\mathbf{n}$ & 18 & & 19 & & \\
\hline Present & 0 & & 2 & 10.5 & \\
\hline Absent & 18 & 100.0 & 17 & 89.5 & \\
\hline
\end{tabular}

Note: Percussion pain was absent at pretreatment, days 1 and 7, and months 6, 9 and 12, hence data not shown in above table, Group A: Treated with Ledermix, Group B: Treated with calcium hydroxide, Fisher's Exact tests $=$ Not significant

Percussion pain showed statistically no significant variation between groups at day 3 (present in 1 each [5\%] in both groups) and month 3 (present in 2 [10.5\%] in group $B(n=19)$ and absent in group $A(n=18)$. Percussion pain was absent at pretreatment, days 1 and 7 , and months 6 th, 9th, and 12 th. Months.

c) Swelling

\begin{tabular}{llllll}
\hline Status & Group A & \multicolumn{3}{l}{ Group B } & P value \\
\hline At month 3 & No. & $(\%)$ & No. & $(\%)$ & $0.486^{\text {ns }}$ \\
\hline $\mathbf{n}$ & 18 & & 19 & & \\
\hline Present & 0 & $(0.0)$ & 2 & $(10.5)$ & \\
\hline Absent & 18 & $(100.0)$ & 17 & $(89.5)$ & \\
\hline
\end{tabular}

NOTE: Swelling was absent at pretreatment, days 1, 3 and 7, and 6th, 9th and 12th months, hence data not shown in above table, Group A: Treated with Ledermix, Group B: Treated with calcium hydroxide, Fisher's Exact test ns $=$ Not significant

Swelling statistically showed no significant variation between group $A(n=18)$ and group $B(n=19)$ at month 3 . The swelling was present in only $2(10.5 \%)$ of group B patients. No swelling was observed in either group at pretreatment, days 1,3 and 7 , or 6 th, 9th and 12 th months.

In both, the groups, mobility and sinus tract was normal at pretreatment, days 1,3 and 7 , and months $3,6,9$ and 12 .

Table-V. Pre-treatment and post-treatment radiological evaluation

\section{a) Periapical radiolucency}

\begin{tabular}{llllll}
\hline Status & Group A & Group B & P value \\
\hline At month 3 & No. & $(\%)$ & No. & $(\%)$ & $1.000^{\text {ns }}$ \\
\hline $\mathbf{n}$ & 18 & & 19 & & \\
\hline Positive & 0 & & 1 & $(5.3)$ & \\
\hline Negative & 18 & $(100.0)$ & 18 & $(94.7)$ & \\
\hline
\end{tabular}

NOTE: Periapical radiolucency was absent at pretreatment, days 1,3 and 7 , and 6th, 9th and 12th months, hence data not shown in above table Group A: Treated with Ledermix Group B: Treated with calcium hydroxide Fisher's Exact test $n s=$ Not significant

Table- $V$ shows the radiological findings of group A and group B patients at pretreatment and post-treatment. Periapical radiolucency at 3 months was present in only $1(5.3 \%)$ of group $B(n=19)$ patients and none in group $A(n=18)$. Statistically no significant variation. At pretreatment and days 1,3 and 7 , and 6 th, 9th and 12th months, no periapical radiolucency was observed in either group A or group B.

On radiology, external root resorption and internal root resorption were absent in both groups $A$ and $B$ at pretreatment, days 1, 3 and 7, and 3rd 6th, 9th and 12th months. 


\section{b. Secondary dentin formation}

\begin{tabular}{llllll}
\hline Status & Group A & \multicolumn{3}{l}{ Group B } & P value \\
\hline At month $\mathbf{3}$ & No. & $(\%)$ & No. & $(\%)$ & $0.264^{\text {ns }}$ \\
\hline $\mathbf{n}$ & 18 & & 17 & & \\
\hline Positive & 11 & $(61.1)$ & 14 & $(82.4)$ & \\
\hline Negative & 7 & $(38.9)$ & 3 & $(17.6)$ & \\
\hline At month 12 & & & & & $0.471^{\text {ns }}$ \\
\hline $\mathbf{n}$ & 18 & & 17 & & \\
\hline Positive & 11 & $(61.1)$ & 13 & $(76.5)$ & \\
\hline Negative & 7 & $(38.9)$ & 4 & $(23.5)$ & \\
\hline & & & & &
\end{tabular}

NOTE: Secondary dentin formation was absent at pretreatment, days 1, 3 and 7, and 3rd and 6th months, hence data not shown in above table, Group A: Treated with Ledermix, Group B: Treated with calcium hydroxide Fisher's Exact test, $\mathrm{ns}=$ Not significant

On radiological evaluation, secondary dentin formation showed no significant variation between group $A(n=18)$ and group $B(n=17)$ at 9 and 12 months. Secondary dentin formation was seen at 9 months in 7 (38.9\%) and $3(17.6 \%)$, and at 12 months in $7(38.9 \%)$ and $4(23.5 \%)$ of group A and group B patients, respectively. No secondary dentin formation was observed at pretreatment, days 1,3 and 7 , and 3rd and 6th months.

Table-VI. Post-treatment outcome of an intervention

\begin{tabular}{|c|c|c|c|c|c|}
\hline Status & Grol & & Gro & & $P$ value \\
\hline & No. & (\%) & No. & (\%) & \\
\hline At day 1 & & & & & $1.000^{\text {ns }}$ \\
\hline $\mathrm{n}$ & 20 & & 20 & & \\
\hline Success & 19 & (95.0) & 20 & (100.0) & \\
\hline Failure & 1 & (5.0) & 0 & $(0.0)$ & \\
\hline At day 3 & & & & & $1.000^{\text {ns }}$ \\
\hline $\mathrm{n}$ & 19 & & 20 & & \\
\hline Success & 18 & (94.7) & 19 & (95.0) & \\
\hline Failure & 1 & (5.3) & 1 & (5.0) & \\
\hline At month 3 & & & & & $0.486^{\text {ns }}$ \\
\hline $\mathrm{n}$ & 18 & & 19 & & \\
\hline Success & 18 & (100.0) & 17 & (89.5) & \\
\hline Failure & 0 & $(0.0)$ & 2 & (10.5) & \\
\hline Overall & & & & & $1.000^{\text {ns }}$ \\
\hline$n$ & 20 & & 20 & & \\
\hline Success & 18 & $(90.0)$ & 17 & (85.0) & \\
\hline Failure & 2 & (10.0) & 3 & (15.0) & \\
\hline
\end{tabular}

NOTE: Since there was no failure at day 7 , and 6th, 9th and 12th months, hence data not shown in above table, Group A: Treated with Ledermix, Group B: Treated with calcium hydroxide. Fisher's Exact test, ns = Not significant Table-VI shows the outcome of the intervention in group A and group $B$ patients. At day 1 , statistically, there was no significant variation between groups, in group A $(n=20)$ there was $1(5 \%)$ failure only and none in group $B$ $(n=20)$. At day 3 , there was $1(5.3 \%)$ failure in group $A(n=19)$ and $1(5 \%)$ in group $B(n=20)$ (statistically no significant variation). At month 3 , in group $A$ $(n=18)$, there was no failure, and in group $B(n=19)$, there was $2(10.5 \%)$ failure (statistically no significant variation).

Overall, in group $A(n=20)$, there were $2(10 \%)$ failures, and in group $B(n=20)$, there were $3(15 \%)$ failures. However, statistically, the success and failure showed no significant variation between groups.

FOLLOW-UP

From day-1 to 3-months following treatment, in both clinical and radiographic assessment, ledermix demonstrated a $100 \%$ achievement rate. Post-operative swelling, tenderness or mobility was absent regardless. There was likewise no indication of radiolucent zone, in the radiographic assessment. At third month follow up, in any case, two patients from the ledermix group reported spontaneous pain however when a radiographic assessment was done, there was no indication of

10| P a g e radiolucency in the apical and furcation zone. In $\mathrm{Ca}(\mathrm{OH}) 2$ group, just a single patient complained about spontaneous paint and swelling was present in two patients. With the exception of this case, the general evaluation of ledermix and $\mathrm{Ca}(\mathrm{OH}) 2$ treatment were effective. Postoperative swelling, tenderness, mobility, and sinus formation was absent. The radiographic assessment likewise demonstrated no radiolucency in any cases.

\section{DISCUSSION}

The choice for IPT, in this case, was based on careful pulp diagnosis, which was supported by evaluation of the history of pain, symptoms and clinical and radiographic findings. Caries removal is a very basic goal in dentistry. When there is significant caries, each therapeutic dental practitioners face the test and bind with the subject of the best methodology: is it better to oust all caries regardless the chance of pulpal exposure, or stop to safeguard the pulp exposure? Right when this hypothetical circumstance with this question is accessible to practitioners, simply $17 \%$ responded that they would stop, leave remaining caries set up and restore the tooth. Several examinations were performed to compare the restoration of partial caries removal with complete caries removal and found identical success. Partial caries removal constrains the chance of presentation of pulp during a removal of caries.After cavity preparation, if all carious dentin was removed except for the bit that would reveal the pulp, followed by placement of pulp capping material, three specific sorts of new dentin response occurs as a result of indirect pulp capping material: (1) cell fibrillar dentin following 2 months of treatment, (2) proximity of globular dentin during the underlying 3 months, and (3) tubular dentin in an even more reliably mineralized pattern.In the present investigation, 40 permanent teeth was treated either by ledermix or $\mathrm{Ca}(\mathrm{OH}) 2$ and the clinical results at 3, 6, and a year interims were inspected; the appraisal was performed by clinical and radiological assessments. The aftereffect of the present investigation in regards to indirect pulp capping with ledermix, all cases demonstrated effective at 3, 6, and a year following treatment yet two cases revealed spontaneous pain at 3 months. Anyway in $\mathrm{Ca}(\mathrm{OH}) 2$ group one had spontaneous pain and two patients had mild pain with swelling. In those cases root canal treatment was done. The specific explanation of failure of these case isn't obviously under stood however, it may have different causes, for example, bacterial infection or, physical, chemical or traumatic mishaps. Another cause we predicted for the failure is due to micro leakage if coronal restoration was not properly sealed.

Rapid and efficient pain relief is of major priority after tooth preparation as there is a considerable loss of dentine. In the recent context, a randomized clinical study is going on regarding the influence of Ledermix cement in reducing postoperative pain which is compared to calcium hydroxide-based cement.The application of Ledermix has been recommended mainly for endodontic treatment, and the relief of pain induced by pulp irritation. The efficacy of its active agents has 
been controversial. Different authors have reported the advantages of using Ledermix for pain reduction in endodontic procedures (Ehrmann EH. 1965) (Ehrmann EH et al 2003) (Mohammadi Z.2009)( Chance $\mathrm{K}$ et al.1987), However, other authors didn't mention any significant differences between Ledermix and calcium hydroxide after intraarticular application concerning pain reduction ( Trope M. 1990) (Marshall JG,1993).

To the best of our knowledge, we only found few studies reporting the efficacy of Ledermix as a temporary cement on vital teeth, especially in cases of the extensive crown and cavity preparations. Abbott et al. report a beneficial effect of Ledermix in the treatment of cracked teeth with clinical signs of reversible pulpitis. Pierce et al was able to show histologically that the application of Ledermix resulted in a reduction of inflammatory external root resorption and thus exerted an inhibitory influence on rapidly progressing root resorptions in injured teeth. Glucocorticoids suppress cellmediated immunity by directly inhibiting all steps within the eicosanoids synthesis. As a consequence, the steroidal component of Ledermix can suppress cell-mediated immunity (Pierce A et al. 1988). Some authors raise concerns that steroids might have an inhibiting effect on the hypo physical system. However, it could be shown that the maximal dose of glucocorticoids applied within the root canal has only a local effect and is therefore not high enough to exert a systemic effect (Abbott PV.1992). The present study uncovered that pulp capping done on teeth with Ledermix cement indicated a fundamentally lower pain observation $24 \mathrm{~h}$ after tooth preparation when contrasted with $\mathrm{Ca}(\mathrm{OH}) 2$ cement. What's more, after $24 \mathrm{~h}$ no huge contrast between the two groups has been found. Over an observational time of 12 weeks, no cases were accounted for with loss of tooth sensitivity, furthermore, the patients had no long term post-operative pain found in both groups.

\section{CONCLUSION}

Bangladesh is a developing country. Endodontic Dentistry in Bangladesh is developing step by step. Continuous exploration of new equipment and materials regularly is mandatory to enrich endodontic dentistry. Identification of a trustworthy pulp capping agent and a suitable delivery technique is challenging. Though $\mathrm{Ca}(\mathrm{OH}) 2$ is widely used, less expensive and gold standard as an indirect pulp capping material, it has no anti-inflammatory action. On the other hand, Ledermix has anti-inflammatory and antibacterial properties. It also can form secondary dentin like $\mathrm{Ca}(\mathrm{OH}) 2$. Ledermix is a progressed and potential indirect pulp capping material for different pulpal methods. In light of this clinical and radiological assessment under the observation of third, sixth and twelfth months development, ledermix pulp capping has a high achievement rate additionally $\mathrm{Ca}(\mathrm{OH}) 2$ as it causes quick and productive help with pain releif. In this way, we concluded that ledermix cement can likewise be utilized as a safe material for indirect pulp capping of permanent teeth.

11| P a g e

\section{REFERENCES:}

1. Abbott PV, Leow N. Predictable management of cracked teeth with reversible pulpitis. Aust Dent J 2009;54:306-315. https://doi.org/10.1111/j.1834-7819.2009.01155.x PMid:20415928

2. Athanassiadis B, Abbott PV, Walsh LJ, The use of calcium hydroxide, antibiotics and biocides as antimicrobial medicaments in endodontics. $\begin{array}{llll}\text { Aust Dent J } & \end{array}$ https://doi.org/10.1111/j.1834-7819.2007.tb00527.x PMid:17546863

3. Abbott PV. Systemic release of corticoids following intra-dental use. IntEndod J. 1992;25:189-191.

https://doi.org/10.1111/j.1365-2591.1992.tb00748.x PMid:1399069

4. Baume L, Holz J. Long-term clinical assessment of direct pulp capping International Dental Journal 1981; 31(4):251-260. https://doi.org/10.1270/jsbbs1951.31.251

5. Bjørndal L, Kidd EA.The treatment of deep dentine caries lesions. Dent Update.2005;32(7):402-13.

https://doi.org/10.12968/denu.2005.32.7.402

PMid:16178284

6. Blitzer MH. Root canal therapy. Use of a combination of antibacterial agents, hydrocortisone and hyaluronidase. NY State Dent J 1956: 22: 503-508

https://doi.org/10.1016/S0031-8914(56)80061-X

7. Bjørndal L. Dentin and pulp reactions to caries and operative treatment: biological variables affecting treatment outcome. Endod Topics.2002;2(1):10-23. https://doi.org/10.1034/j.1601-1546.2002.20102.x

8. Cox C, Subay R, Ostro E, Suzuki S, Suzuki SH. Tunnel defects in dentin bridges: Their formation following direct pulp capping. Operative Dentistry 1996;21(1):4-11. [PubMed: 8957909].

9. Chance $\mathrm{K}$, Lin L, Shovlin FE, Skribner J. Clinical trial of intracanal corticosteroid in root canal therapy. J Endod. 1987;13:466-468. https://doi.org/10.1016/S0099-2399(87)80066-3

10. Eidelman E, Finn SB, Koulourides T. Remineralization of carious dentin treated with calcium hydroxide, J Dent Child 1965;32:218-25. https://doi.org/10.1016/0003-4916(65)90016-3

11. Ehrmann EH. The effect of triamcinolone with tetracycline on the dental pulp and apical periodontium. J Prosthet Dent. 1965;15:144-152. https://doi.org/10.1016/0022-3913(65)90074-0

12. Ehrmann EH, Messer HH, Adams GG. The relationship of intracanal medicaments to postoperative pain in endodontics. IntEndod J. 2003;36:868-875.

https://doi.org/10.1111/i.1365-2591.2003.00735.x PMid:14641427

13. Graham L, Cooper PR, Cassidy N, et al. The effect of calcium hydroxide on solubilisation of bioactive dentine matrix components. Biomaterials 2006;27:2865-73.

https://doi.org/10.1016/i.biomaterials.2005.12.020 PMid:16427123

14. Greely CB. Pulp therapy for the primary and young permanent dentition. In: $\quad$ Forrester DJ, Wagner ML, Fleming J, editors. Pediatric dental medicine Philadelphia: Lea \&Febiger; 1981. p. 456-60.

15. Heithersay GS, Hume WR, Abbott PV. Conventional root canal therapy, II: Intracanal medication. IN: Harty FJ, Ed. Endodontics in Clinical Practice 3rd Edition

16. Dental Practitioner Handbook No. 24, Wright Butterworth Scientific, London 1990;162-85.

17. Hume WR, KENNEY AE. Release of'H-triamcinolone from Ledermix.JEndod $\quad 1981 ; \quad 7: \quad 509-14.17$. https://doi.org/10.1016/S0099-2399(81)80113-6

18. Hume WR. An analysis of the release and the diffusion through dentin of eugenol from zinc oxide-eugenol mixtures. J Dent Res 1984;63:881-4. https://doi.org/10.1177/00220345840630061301 PMid:6588071

Website: https://www.banglajol.info/index.php/UpDCJ 
19. Hume WR. The pharmacologic and toxicological properties of zinc oxideeugenol. J Am Dent Assoc 1986; 113:789-91.

20. Kopel HM 1992, 'Considerations for the direct pulp capping procedure in the primary teeth: areview of the literature' ASDC J Dent Child vol.59 pp.141-149.

21. Kitasako $Y$, Ikeda $M$, Tagami J. Pulpal responses to bacterial contamination following dentin bridging beneath hard-setting calcium hydroxide and self-etching adhesive resin system. Dental Traumatology 2008;24:201-206. [PubMed: 18352925]. https://doi.org/10.1111/j.1600-9657.2007.00517.x

PMid:18352925

22. Miyashita H, Worthington HV, Qualtrough A, Plasschaert A. Pulp management for caries in adults: maintaining pulp vitality. Cochrane Database Syst Rev. 2007;18(2):CD004484.

23. Mohammadi Z. Systemic and local applications of steroids in endodontics: an update review. Int Dent J. 2009;59:297-304. https://doi.org/10.3161/000345409X476387

24. Marshall JG, Liesinger AW. Factors associated with endodontic posttreatment pain. J Endod. 1993;19:573-575. https://doi.org/10.1016/S0099-2399(06)81290-2

25. Oliveira EF, Carminatti G, Fontanella V, Maltz M. The monitoring of deep caries lesions after incomplete dentine caries removal: results after 1418 months. Clin Oral Investig.2006;10(2):134-9. https://doi.org/10.1007/s00784-006-0033-8

PMid:16550396

26. Pierce $A M$, Lindskog $S$. The effect of an antibiotic/corticosteroid paste on inflammatory root resorption in vivo. Oral Surg Oral Med Oral Pathol 1987; 64:216-20. https://doi.org/10.1016/0030-4220(87)90094-6

27. Pierce AM, Heithersay GS, LindskogS.Evidence for direct inhibition of dentinoclasts by a corticosteroid/antibiotic paste. Endod Dent Traumatol 1988;4:44-5. RC. Corticosteroids and https://doi.org/10.1111/j.1600-9657.1988.tb00292.x PMid:3151884

28. Prosser $H$, Groffman D, Wilson D. The effect of composition on the erosion properties of calcium hydroxide cements. Journal of Dental Research 1982;61(12):1431-1435. [PubMed: 6960048]

29. Sayegh FS. Qualitative and quantitative evaluation of new dentin in pulp capped teeth. J Dent Child 1968; 35:7

30. Trope M. Relationship of intracanal medicaments to endodontic flareups. Endod Dent Traumatol. 1990;6:226-229. https://doi.org/10.1111/j.1600-9657.1990.tb00423.x PMid:2133314 